NASA Technical Memorandum 105230

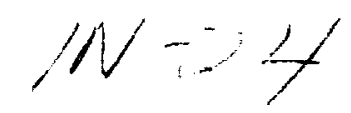

45766

p. 35

\title{
Progressive Fracture in Composites Subjected to Hygrothermal Environment
}

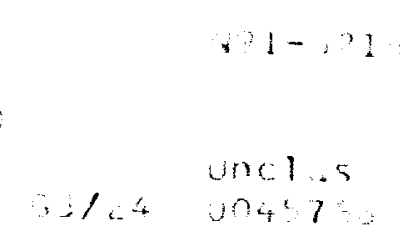

Levon Minnetyan

Clarkson University

Potsdam, New York

Pappu L.N. Murthy and Christos C. Chamis

Lewis Research Center

Cleveland, Ohio

Prepared for the

32nd Structures, Structural Dynamics, and Materials Conference

cosponsored by AIAA, ASME, ASCE, AHS, and ASC

Baltimore, Maryland, April 8-10, 1991 


\title{
Progressive Fracture in Composites Subjected to Hygrothermal Environment
}

\author{
Levon Minnetyan* \\ Clarkson University \\ Potsdam, New York 13699-5710 \\ Pappu L.N. Murthy ${ }^{\dagger}$ and Christos C. Chamis ${ }^{\ddagger}$ \\ National Aeronautics and Space Administration \\ Lewis Research Center \\ Cleveland, Ohio 44135
}

\section{Abstract}

The influence of hygrothermal environmental conditions on the load carrying ability and response of composite structures are investigated via computational simulation. An integrated computer code is utilized for the simulation of composite structural degradation under loading. Damage initiation, damage growth, fracture progression, and global structural fracture are included in the simulation. Results demonstrate the significance of hygro-thermal effects on composite structural response, toughness, and durability.

\section{Introduction}

Composite structures lend themselves to tailoring to achieve desirable characteristics such as a high strength to weight ratio and dimensional stability under extreme thermal and hygral fluctuations. Applications of composites in airframes, engine structures, space structures, marine and surface transportation structures, and high precision machinery require near flawless structural performance even when exposed to adverse loading and environmental

*Associate Professor, Department of Civil and Environmental Engineering.

${ }^{\dagger}$ Aerospace Engineer, Structures Division.

†Senior Aerospace Scientist, Structures Division. 
effects during service. Efficient structural design requires reliable computational simulation and prediction capabilities for the behavior of composite structures under typical service conditions and possible overloading. Design specifications require accurate prediction of composite properties under the expected range of environmental conditions. Structural response characteristics and durability of composites depend upon their exposure to various hygro-thermal conditions as well as mechanical loading. Accordingly, a helpful tool for the design of composite structures is the capability to simulate the response of any structure possessing arbitrary material properties, under any loading or environmental effects. The design of laminated composite structures requires the prediction of overall structural properties, damage resistance, fracture toughness, and durability, given the constituent thermomechanical properties and fiber orientations. The effects of static, dynamic, point impact, shock pressure, cyclic fatigue, and thermal loading, as well as that of the hygro-thermal environment are often important design concerns.

In polymer-matrix composites, effects of the hygro-thermal environment are primarily observed in the matrix properties. Composite strength is closely related to the strength and orientations of the fibers. Nevertheless, matrix properties have a fundamental effect on damage resistance and structural durability. Matrix properties are a deciding factor with respect to the location and nature of damage initiation, damage growth, and subsequent damage progression. For most composite structures, initial damage occurs in the matrix material as transverse tensile failure or shear failure depending on geometry and loading.

The behavior of laminated composite structures under loading is rather complex, especially when possible degradation with damage and fracture propagation is to be considered. After the initiation of damage, damage growth and progression usually involves fiber-matrix debonding within individual plies and the propagation of the damage zone. Further degradation in the form of fiber fracture leads to laminate fracture and on to structural fracture. Because of the numerous possible combinations of material, ply orientations, and loading 
conditions, it is essential to have a reliable computational capability to predict the behavior of composites under general loading and boundary conditions. The predictions of damage initiation, growth, and fracture are important in evaluating the safety and reliability of composite structures. Information on the fracture resistance of a laminated composite structure is also fundamental for evaluation of its safety and reliability under loading.

\section{Background and Objective}

The effect of the hygro-thermal environment on the performance of composites has been the subject of numerous investigations. Simplified procedures for incorporating hygro-thermal effects into composite behavior have been given. ${ }^{1}$ Experimental and numerical results relating the hygro-thermal effects on flexural and interlaminar strength and defect growth in composites have been reported. ${ }^{2}$ The influence of hygro-thermal effects on the free-edge delamination in composites has been investigated. ${ }^{3}$ Hygro-thermal effects have been included in an optimal design procedure for composite turbine blades. ${ }^{4}$ Effects of the hygro-thermal environment on damping properties of composites have been investigated. ${ }^{5}$ Hygro-thermal effects have been included in the formulation of design procedures for fiber composite structural components and joints. ${ }^{6}$ The Integrated Composite ANalyzer (ICAN) code has incorporated hygro-thermal effects in the prediction of through-the-thickness stress-strain relationships and strength of laminated composites. ${ }^{7}$ The fatigue of fiber composite structures under hygrothermomechanical cyclic loading has also been investigated. ${ }^{8}$

Computational simulation methods relating the constitutive properties of materials to the overall structural behavior and damage resistance of polymer matrix and hybrid laminated composites are based upon micromechanics relationships that are consolidated in the ICAN computer code. The ICAN code incorporates the cumulative result of composites research at NASA-Lewis Research Center on polymer matrix multi-layer angle-plied com-

posites. ICAN is capable of determining the ability of the laminated composite to endure 
stresses and deformations caused by applied loading and environmental effects such as temperature and moisture. All practical modes of internal damage and fracture in composite laminates are predicted. A resident data bank contains the properties of typical fiber and matrix constituent materials, with provisions to add new constituents as they become available.

The influences of most loading and environmental conditions on material properties are interrelated. Micromechanics constitutive relationships implemented in ICAN are based on interaction equations that include the combined effects of all relevant conditions on the material behavior. Composite analysis carried out by ICAN has been demonstrated, tested, and verified from many perspectives. Computational composite mechanics provided by ICAN is a fundamental resource in the development of design evaluation methodologies for the structural response and integrity of polymer-matrix composites.

The constituent micromechanics relationships quantify degradation of matrix strength and moduli with increasing temperature and moisture. The effect of the reduction in matrix strength and moduli on the overall composite properties, strength, and durability is not easily predictable. The effect of matrix degradation on the overall composite depends upon the fiber properties and orientation of the plies, as well as matrix properties.

Previous investigations of hygro-thermal effects on composites have concentrated on the effects of temperature and moisture on composite structural properties and damage initiation propensity. The objective of the current paper is to extend the investigation of hygro-thermal effects with regard to structural durability and with regard to the changes in structural properties as composite degradation occurs. Existing validated computational infrastructures are used to simulate the changes in structural durability, and degradation behavior of overall composite structural properties under loading, in relation to the hygro-thermal conditions. In the present investigation, the ICAN $\operatorname{code}^{7}$ is used as the micromechanics module that is combined with a finite element analysis $\operatorname{code}^{9}$ and an executive module for durability 
and degradation analysis, to form the COmposite Durability STRuctural ANalyzer (CODSTRAN) computer code. CODSTRAN is able to simulate composite damage initiation and growth under various loading and hygro-thermal conditions. The concept and foundations of the computational simulation of composite structural durability were first laid out by the original implementation of the CODSTRAN code. ${ }^{10}$ The simulation of progressive fracture by CODSTRAN was verified to be in reasonable agreement with experimental data from tensile tests. ${ }^{11}$ Recent additions to CODSTRAN have enabled monitoring the variations in structural properties such as natural frequencies, vibration mode shapes, buckling loads, and buckling modes during progressive fracture. ${ }^{12} \mathrm{~A}$ dynamic analysis capability has been implemented to evaluate degradation under impulsive loads. ${ }^{13}$ More recently a quantitative measure of structural damage and computation of the strain energy release rate were added to the code to develop a computational evaluation of the structural resistance to global fracture for laminated composite structures. ${ }^{14}$ The capability to quantify load-induced damage in the composite structure and to relate this damage to changes in measurable structural properties is a convenient feature of the recently augmented code. Combining this feature with the evaluation of fracture toughness during damage progression, the code is able to prcdict the amount of internal damage as well as the fracture stability and safety of the damaged composite. The relationship between internal damage and structural properties such as natural frequencies and vibration mode shapes is useful for the in-service evaluation of safety and reliability. In this way composite structural behavior can be evaluated under any loading condition, geometry, or boundary conditions.

\section{Computational Method}

The CODSTRAN computer code has been synthesized from three modules: The overall conduct of composite durability analysis is carried out in an executive module $e^{10}$ that evaluates failure and keeps track of composite degradation for the entire structure. The executive mod- 
ule references the ICAN analysis package for micromechanics, macromechanics and laminate theory $^{7}$, and a finite element analysis module with anisotropic thick shell analysis capability. ${ }^{9}$ A flow chart of CODSTRAN is given in Figure 1.

The effects of moisture and temperature on mechanical properties of composite constituents are taken into account in the composite mechanics module (ICAN). ${ }^{7}$ The ICAN module is referenced before and after each finite element analysis. Figure 2 depicts the tasks performed by ICAN in a CODSTRAN analysis step. Prior to a finite element analysis the ICAN module computes the overall composite properties depending on the fiber and matrix constituent characteristics and the composite layup. The coupled effects of thermal and hygral conditions on structural properties and composite durability are taken into account in the constitutive relationships. ${ }^{1}$ The anisotropic relationships between generalized stresses and strains are computed for each node by the ICAN module and supplied to the finite element analysis module. Generalized stresses in thick shell finite element analysis consist of the in-plane normal and shear (membrane), out of plane bending and twisting, and through the thickness shear stresses. The finite element analysis module accepts the overall composite properties that are computed by the ICAN module at each node to assemble the finite element equations and to carry out the analysis under a load increment. After the conduct of a finite element analysis, the computed generalized stresses are supplied to the ICAN module that computes the ply stresses to evaluate the nature and amount of damage in the plies of the composite laminate. Individual ply failure modes checked by CODSTRAN include the failure criteria associated with the negative and positive limits of the six ply-stress components $\left(\sigma_{\ell 11}, \sigma_{\ell 22}, \sigma_{\ell 33}, \sigma_{\ell 12}, \sigma_{\ell 23}, \sigma_{\ell 13}\right)$ and a combined stress strength criterion. ${ }^{7}$

The executive module references the ICAN and finite element modules, keeping track of the structural damage under loading and carrying out the overall computational simulation of composite response, degradation, and fracture. The executive module updates the generalized stress-strain relationships for each node according to the composite damage evaluated 
by the ICAN module after a structural analysis step by the finite element module. The incremental loading procedure uses a step size criterion based on the allowable maximum number of damaged and fractured nodes during the application of a load increment. In this study, the step size criterion is set so that no more than four nodes may be damaged in any load increment. If more than four nodes are damaged or fractured during a load increment, incremental loads are reduced and the analysis is repeated. Otherwise, if there is an acceptable amount of damage, the load increment is kept constant but the overall composite properties are reevaluated and structural geometry is updated to account for incremental damage and deformations. When all failure criteria are met at a node, that node is deleted and new detached nodes are created at the same point for the remaining adjacent elements. After reconstituting the new computational model with updated finite element mesh and

material properties, the structure is reanalyzed for further damage and deformation. If, after an incremental analysis step, there is no damage, the structure is considered to be in equilibrium and an additional load increment is applied. Analysis is stopped when global structural fracture is predicted.

\section{Example Composite Structures and Analysis}

Three composite systems are studied. An intermediate stiffness, T-300/Epoxy composite laminate is selected as a first demonstration example. A rectangular composite plate that is 6 in. long, 3 in. wide and 0.02 in. thick, with a 0.625 in. central notch is used (Figure 3a). The finite element model consists of seventy rectangular four-node isoparametric shell elements $^{9}$ as shown in Figure $3 \mathrm{~b}$. The plate is subjected to a uniaxial in-plane tensile loading. The laminate configuration is $+15 /-15 /-15 /+15$ degrees, with zero degrees corresponding to the direction of the applied loading. The plate is clamped at one end, laterally supported along the opposite end where the tensile loading is applied, and unsupported along the remaining two sides. Progressive damage and fracture evolve as the applied loading is 
increased. Changes in the first three natural frequencies and the first buckling load are computed. The buckling load is taken as a uniformly distributed compressive load applied in the reverse sense of the tensile loading. The overall internal damage is computed as a measure of composite structural degradation. Six cases of temperature and moisture combinations are considered. Service temperatures of 70, 200, and 300 degrees Fahrenheit are considered with moisture contents of either 0 or 1 percent. The progression of damage and fracture is evaluated for each case.

Table 1 shows the total tensile load carried by the composite at four different stages of loading under varied hygro-thermal conditions. Of the given four loading stages, the initial fracture load is defined as the load to initiate a through-the-thickness laceration of the composite at one node. There may be degradation due to ply damage prior to the throughthe-thickness fracture of the laminate. The secondary fracture load is the load that causes either propagation of the initial fracture or initiation of fracture at another location. The critical load is the load corresponding to the minimum value of the strain energy release rate (SERR) during fracture progression. As defined in reference ${ }^{\mathbf{1 4}}$, the minimum value of the SERR represents a critical stage of loading that signals the approach of global fracture. CODSTRAN analysis indicates that composite structures may show some additional resistance to increased loading after the critical load. However, in an actual loading condition, damage propagation induces load fluctuations and the structure is not likely to survive beyond the critical load. This is due to the low level of SERR at this stage, indicating that the structure is showing little resistance against fracture propagation. The global fracture load is the final load at which CODSTRAN predicts the laminate is broken apart into two pieces under static loading.

Figure 4 shows the relationship between the applied loading and the resulting internal damage in the composite for the temperature and moisture combinations considered. The individual load-damage curves terminate when the composite plate is broken into two pieces. 
The applied loading is the total in-plane tensile load in the longitudinal direction of the plate. Figure 4 indicates that the overall strength of the composite structure is reduced with increasing temperature. In general, it is observed that increasing moisture also reduces the structural strength. However, the effect of moisture on strength becomes more important at higher temperatures. For temperatures of 70 or 200 degrees at either zero or one percent moisture content, initial damage happens at the same load level. However, damage growth and fracture progression vary considerably. When the service temperature is 300 degrees, initial damage starts under a lower loading.

The overall quantity of damage includes individual ply damage as well as through-thethickness fracture of the composite laminate. The details of damage computation are given in reference. ${ }^{14}$ The definition of damage in this paper is such that the composite structure would be considered 100 percent damaged if all plies of all nodes were to develop some damage. In general, global fracture or structural fracture will occur before the 100 percent damage level is reached. Computed results up to impending global fracture of the composite structure are presented as described below.

Figures $5,6,7$, and 8 show the changes in the first three natural frequencies and the first buckling load, respectively, as functions of the applied load and also as functions of the load-induced damage for the six hygro-thermal conditions considered. An interesting observation from these figures is that the case corresponding to the most severe hygrothermal environment considered (300 degree temperature and one percent moisture) shows the least sensitivity of its structural properties to damage. The reason for this is that the reduction of matrix moduli due to moisture and temperature makes part of the composite structure more compliant without showing excessive changes in the global structural response. However, the adverse hygro-thermal conditions also degrade the strength of the overall structure; resulting in the separation of the composite into two pieces under a lower loading, as seen from Table 1. For the case of one percent moisture, at the $300^{\circ} \mathrm{F}$ temperature, the apparent structural 
response properties remain considerably high even when the composite is being torn into two pieces. This phenomenon is because the restrained half of the composite laminate has absorbed most of the damage and fracture due to overconstrained boundary conditions, and the computed vibration frequencies represent merely the other half of the structure that has been spared degradation.

A second example uses the same T-300/Epoxy composite as in the first example. However, the ply fiber orientations are changed to $0 / 90 / 90 / 0$ degrees with respect to the loading direction. The combinations of loading and environmental conditions are the same as in the first case. Figure 9 shows the relationships between the applied load and the produced damage for this composite. Table 2 shows the four loading stages corresponding to initial and secondary fracture, critical stage, and global fracture, under the six hygro-thermal conditions considered. Strength of the composite structure is considerably lower compared to the first example because half of the plies have their fibers orthogonal to the direction of loading in this case. Also, the difference between the damage initiation load and the global fracture load is less than the first example because of fiber orientation. Higher temperature and moisture levels significantly reduce the strength of the composite as usual. Figures 10 through 13 show changes in the first three natural frequencies and the first buckling load in relation to the applied load and also in relation to the load-induced damage.

For a hind exanple, a composite structure with the same geometry and fiber orientations as in the first case but made of a different composite system is considered. The composite system for the third example is S-Glass/high modulus, high strength epoxy matrix system (S-Glass/HMHS). Figure 14 shows the relationships between loading and damage for the six hygrothermal conditions on the S-Glass/HMHS composite. This composite shows a more nonlinear behavior with a more uniform distribution of structural damage. Because of the lower fiber strength, initial damage starts at a lower load compared to the T-300/Epoxy composite with the same $( \pm 15)_{\mathrm{s}}$ fiber orientations. Table 3 shows the four load levels for 
the six hygro-thermal conditions on the S-Glass/HMHS composite. The effects of increasing temperature and moisture are to lower the overall structural strength as in the previous cases. However, the degradation process is more complex. Figures 15 through 18 depict the changes in the first three natural frequencies and in the first buckling load, respectively, as functions of the applied load and also as functions of the induced damage. At a service temperature of $300^{\circ} \mathrm{F}$, the fundamental vibration frequency and the first buckling load are temporarily increased after damage. The fluctuations in the natural frequencies and the fundamental buckling load are because of changes in the composite structure from its original plane geometry due to load-induced damage and distortions. Changing the geometric shape of the composite structure causes significant changes in the fundamental vibration and buckling modes that reverberate to the changes in the corresponding natural frequencies and the buckling load. For this particular example, the first vibration mode and the first buckling mode both have their maximum amplitudes at the geometric center of the plate where the initial notch is located. ${ }^{13}$ However, when the geometry is significantly distorted, mode shapes change such that the maximum amplitudes split and move to the sides of the plate away from the notch, increasing the first natural frequency and the first buckling load significantly. If the applied loading is further increased, damage propagation in the distorted regions cause a relief from some of the distortion and cause the maximum modal amplitudes to shift back to the center notch location; thus, the affected natural frequencies and the first buckling mode are reduced back to lower levels. The process continues in cycles as out of plane distortions are formed and relieved repeatedly between the notch and the edge of the plate due to gradually increased loading.

Load induced geometric distortions are significant only at the highest temperature considered. At increased temperatures the polymer-matrix becomes less brittle and redistributes stress more effectively. This thermal softening effect is more pronounced in the S-Glass/HMHS composite because the composite behavior is more strongly influenced by the 
matrix properties. These results are not surprising since hygro-thermal loading is assumed to influence only the matrix properties.

\section{Conclusions}

Computational simulation shows that the strength of a composite structure is in general decreased with increasing temperature and moisture. Also, in general, ductility is increased and stiffness is decreased with increasing temperature. On the other hand, increasing the moisture content does not improve ductility because moisture does not have as much of a softening effect as temperature in the constitutive relationships. Lower temperatures make the composite structure more brittle and facilitate local fracture. As it is observed from the present results, there are exceptions to all of these generalizations.

It would have been difficult to quantify the overall effects of hygro-thermal conditions on structural behavior, damage initiation, and fracture propagation for the specific cases, without the computational simulation capability. The CODSTRAN computer code, using verified micromechanics definitions of material laws, takes into account the effects of temperature and moisture in the prediction of structural behavior and structural durability of composites.

The evaluation of damage in composites is often based upon the measurement of changes in the overall structural properties such as natural frequencies, vibration modes, buckling loads, and buckling modes. Hygro-thermal conditions affect the structural response. For reliable interpretation of NDE measurements under varied environmental conditions it is requisite to evaluate the effects of temperature and moisture on structural behavior. The present computational simulation method illustrates the computation of changes in overall composite properties and durability due to variations in temperature and moisture.

This paper demonstrates that computational simulation, with the use of established composite mechanics and finite element methods, can be used to predict the effects of tem- 
perature and moisture, as well as loading, on structural properties and durability of composites.

\section{Acknowledgment}

The participation of the first author in this research was sponsored by NASA-Lewis Research Center through grant NAG-3-1101 to Clarkson University.

\section{References}

${ }^{1}$ Chamis, C. C., "Simplified Composite Micromechanics Equations for Hygral, Thermal, and Mechanical Properties," NASA TM-83320, February 1983.

${ }^{2}$ Chamis, C. C. and Smith, G. T., "Environmental and High Strain Rate Effects on Composites for Engine Applications," AIAA Journal, V. 22, No. 1, January 1984, pp. $128-134$

${ }^{3}$ Murthy, P. L. N. and Chamis, C. C., "Free-Edge Delamination: Laminate Width and Loading Conditions Effects," NASA TM-100238, December 1987, 27 pp.

${ }^{4}$ Rubenstein, R. and Chamis, C. C., "STAEBL/General Composites With Hygrothermal Effects (STAEBL/GENCOM)," NASA TM-100266, December 1987, 11 pp.

${ }^{5}$ Saravanos, D. A. and Chamis, C. C., "Mechanics of Damping for Fiber Composite Laminates Including Hygro-Thermal Effects," NASA TM-102329, April 1989.

${ }^{6}$ Murthy, P. L. N. and Chamis, C. C., "Simplified Design Procedures for Fiber Composite Structural Components/ Joints," NASA TM-103113, July 1990, 23 pp.

${ }^{7}$ Murthy, P. L. N. and Chamis, C. C., Integrated Composite Analyzer (ICAN): Users and Programmers Manual, NASA Technical Paper 2515, March 1986.

${ }^{8}$ Ginty, C. A. and Chamis, C. C. "Hygrothermomechanical Fiber Composite Fatigue: Computational Simulation," NASA TM-100840, 1988. 
${ }^{9}$ Nakazawa, S., Dias, J. B., and Spiegel, M. S. MHOST Users' Manual, Prepared for NASA Lewis Research Center by MARC Analysis Research Corporation, April 1987. ${ }^{10}$ Chamis, C. C. and Smith, G. T. "Composite Durability Structural Analysis," NASA TM-79070, 1978.

${ }^{11}$ Irvine, T. B. and Ginty, C. A. "Progressive Fracture of Fiber Composites," NASA TM-83701, 1983

${ }^{12}$ Minnetyan, L., Chamis, C. C., and Murthy, P. L. N., "Structural Behavior of Composites with Progressive Fracture," NASA TM-102370, January 1990, 18 pp.

${ }^{13}$ Minnetyan, L., Murthy, P. L. N., and Chamis, C. C., "Progression of Damage and Fracture in Composites under Dynamic Loading," NASA TM-103118, April 1990, 16 pp.

${ }^{14}$ Minnetyan, L., Murthy, P. L. N., and Chamis, C. C. "Composite Structure Global Fracture Toughness via Computational Simulation," Computers \& Structures, Vol. 37 , No. 2, pp.175-180, 1990 
Table 1. T300/Epoxy $( \pm 15)$ s Hygrothermal Environment and Loads.

\begin{tabular}{cccccc}
\hline $\begin{array}{c}\text { Temper- } \\
\text { ature } \\
\left({ }^{\circ} F\right)\end{array}$ & $\begin{array}{c}\text { Mois- } \\
\text { ture } \\
(\%)\end{array}$ & $\begin{array}{c}\text { Initial } \\
\text { Fracture } \\
\text { Load (lbs. })\end{array}$ & $\begin{array}{c}\text { Secondary } \\
\text { Fracture } \\
\text { Load (lbs.) }\end{array}$ & $\begin{array}{c}\text { Critical } \\
\text { Load } \\
(\text { lbs. })\end{array}$ & $\begin{array}{c}\text { Global } \\
\text { Fracture } \\
\text { Load (lbs. })\end{array}$ \\
\hline 70 & 0 & 5200 & 5911 & 6201 & 6201 \\
70 & 1 & 5200 & 5911 & 6201 & 6289 \\
200 & 0 & 5200 & 5714 & 6056 & 6092 \\
200 & 1 & 5200 & 5556 & 5889 & 5940 \\
300 & 0 & 4311 & 5022 & 5464 & 5583 \\
300 & 1 & 4133 & 4370 & 5101 & 5101 \\
\hline \hline
\end{tabular}

Table 2. T300/Epoxy $(0,90)$ s Hygrothermal Environment and Loads.

\begin{tabular}{cccccc}
\hline $\begin{array}{c}\text { Temper- } \\
\text { ature } \\
\left({ }^{\circ} F\right)\end{array}$ & $\begin{array}{c}\text { Mois- } \\
\text { ture } \\
(\%)\end{array}$ & $\begin{array}{c}\text { Initial } \\
\text { Fracture } \\
\text { Load (lbs.) }\end{array}$ & $\begin{array}{c}\text { Secondary } \\
\text { Fracture } \\
\text { Load (lbs.) }\end{array}$ & $\begin{array}{c}\text { Critical } \\
\text { Load } \\
\text { (lbs.) }\end{array}$ & $\begin{array}{c}\text { Global } \\
\text { Fracture } \\
\text { Load (lbs.) }\end{array}$ \\
\hline 70 & 0 & 3600 & 4133 & 4133 & 4133 \\
70 & 1 & 3600 & 3867 & 4190 & 4198 \\
200 & 0 & 3867 & 4117 & 4257 & 4257 \\
200 & 1 & 2800 & 3570 & 3597 & 3938 \\
300 & 0 & 2800 & 3037 & 3037 & 3344 \\
300 & 1 & 2267 & 2533 & 2751 & 2988 \\
\hline
\end{tabular}

Table 3. S-Glass/HMHS ( \pm 15$)$ s Hygrothermal Environment and Loads.

\begin{tabular}{cccccc}
\hline \hline $\begin{array}{c}\text { Temper- } \\
\text { ature } \\
\left({ }^{\circ} F\right)\end{array}$ & $\begin{array}{c}\text { Mois- } \\
\text { ture } \\
(\%)\end{array}$ & $\begin{array}{c}\text { Initial } \\
\text { Fracture } \\
\text { Load (lbs.) }\end{array}$ & $\begin{array}{c}\text { Secondary } \\
\text { Fracture } \\
\text { Load (lbs.) }\end{array}$ & $\begin{array}{c}\text { Critical } \\
\text { Load } \\
(\text { lbs. })\end{array}$ & $\begin{array}{c}\text { Global } \\
\text { Fracture } \\
\text { Load (lbs.) }\end{array}$ \\
\hline 70 & 0 & 4311 & 4667 & 5666 & 6036 \\
70 & 1 & 4667 & 5395 & 5558 & 6093 \\
200 & 0 & 4756 & 4914 & 5366 & 5928 \\
200 & 1 & 4756 & 5541 & 5379 & 6401 \\
300 & 0 & 4281 & 4360 & 4634 & 4983 \\
300 & 1 & 3570 & 3728 & 4915 & 4927 \\
\hline \hline
\end{tabular}




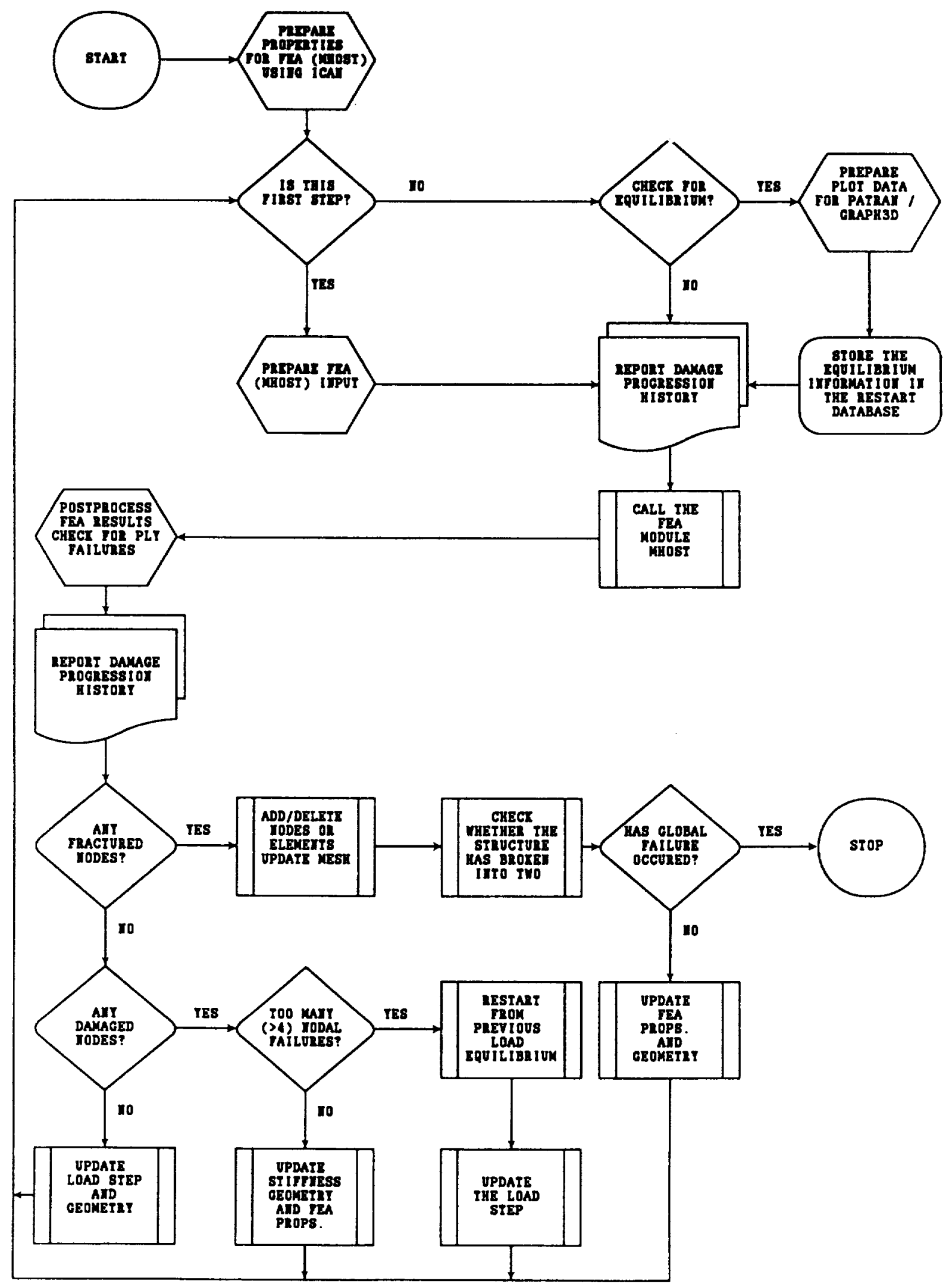

Figure 1 CODSTRAN Flow Chart 


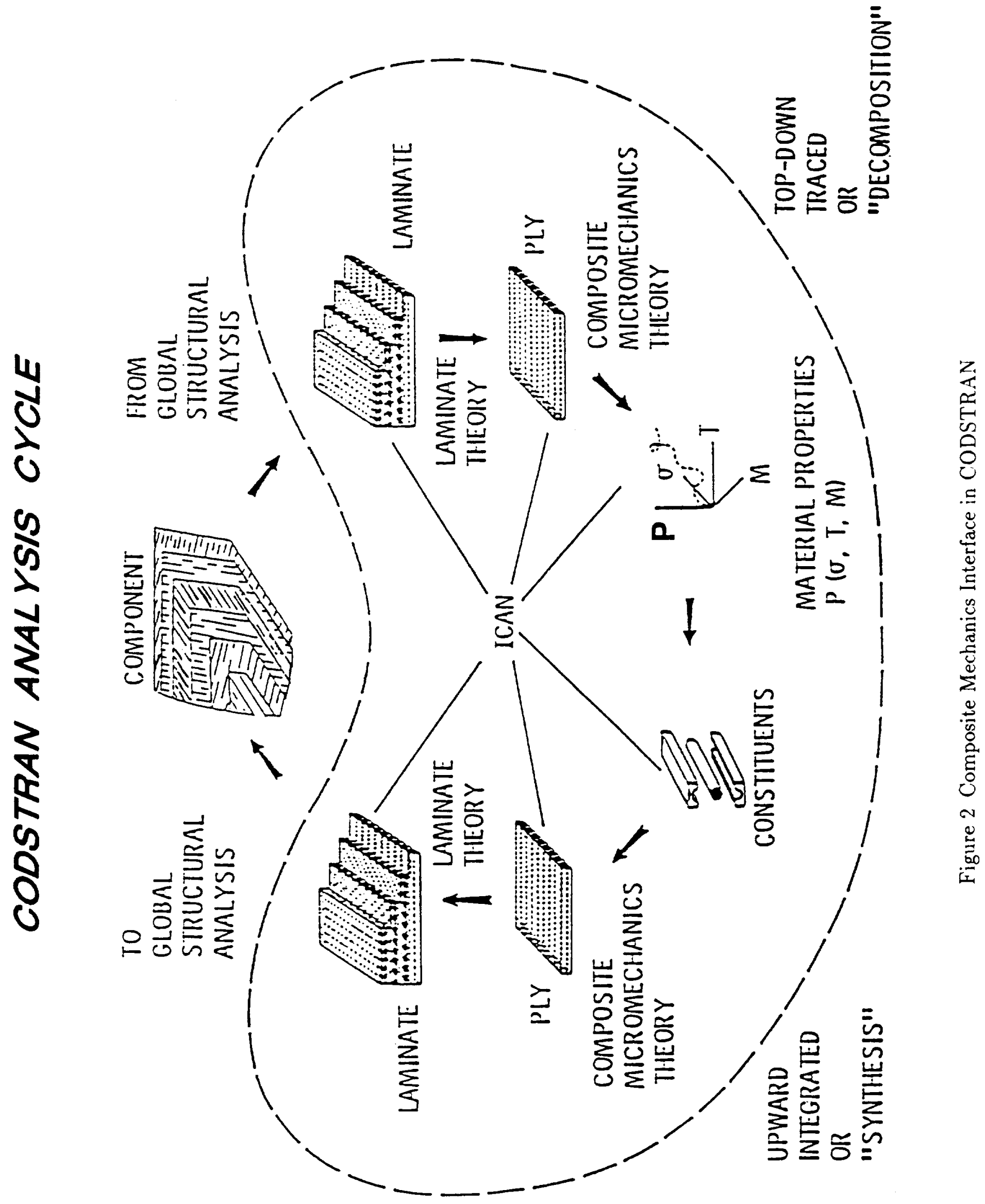




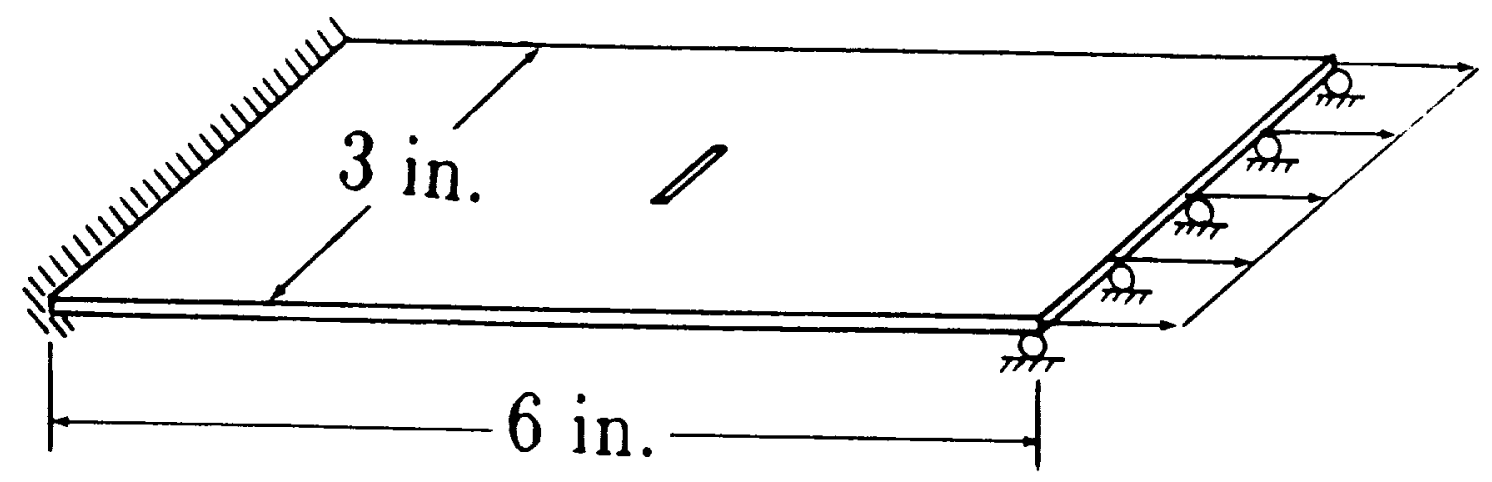

Figure 3a Example Structure and Loading

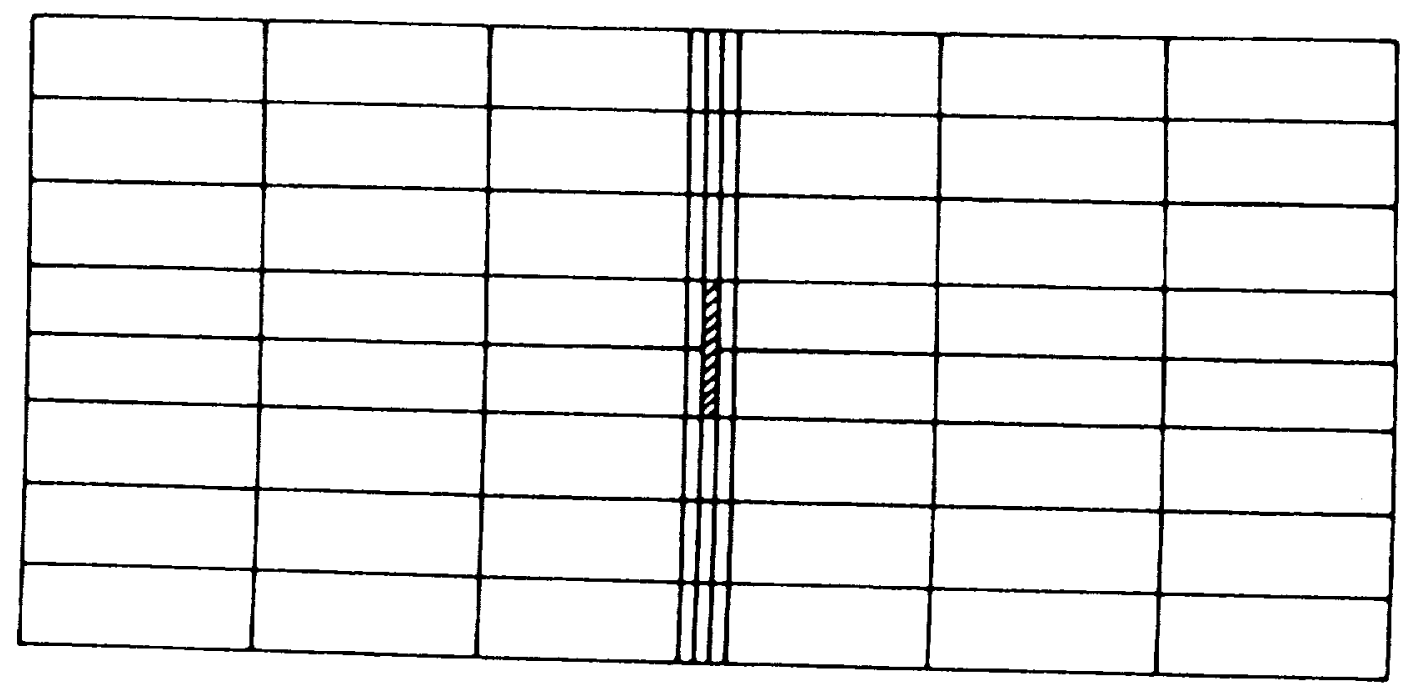

Figure 3b Finite Element Model 


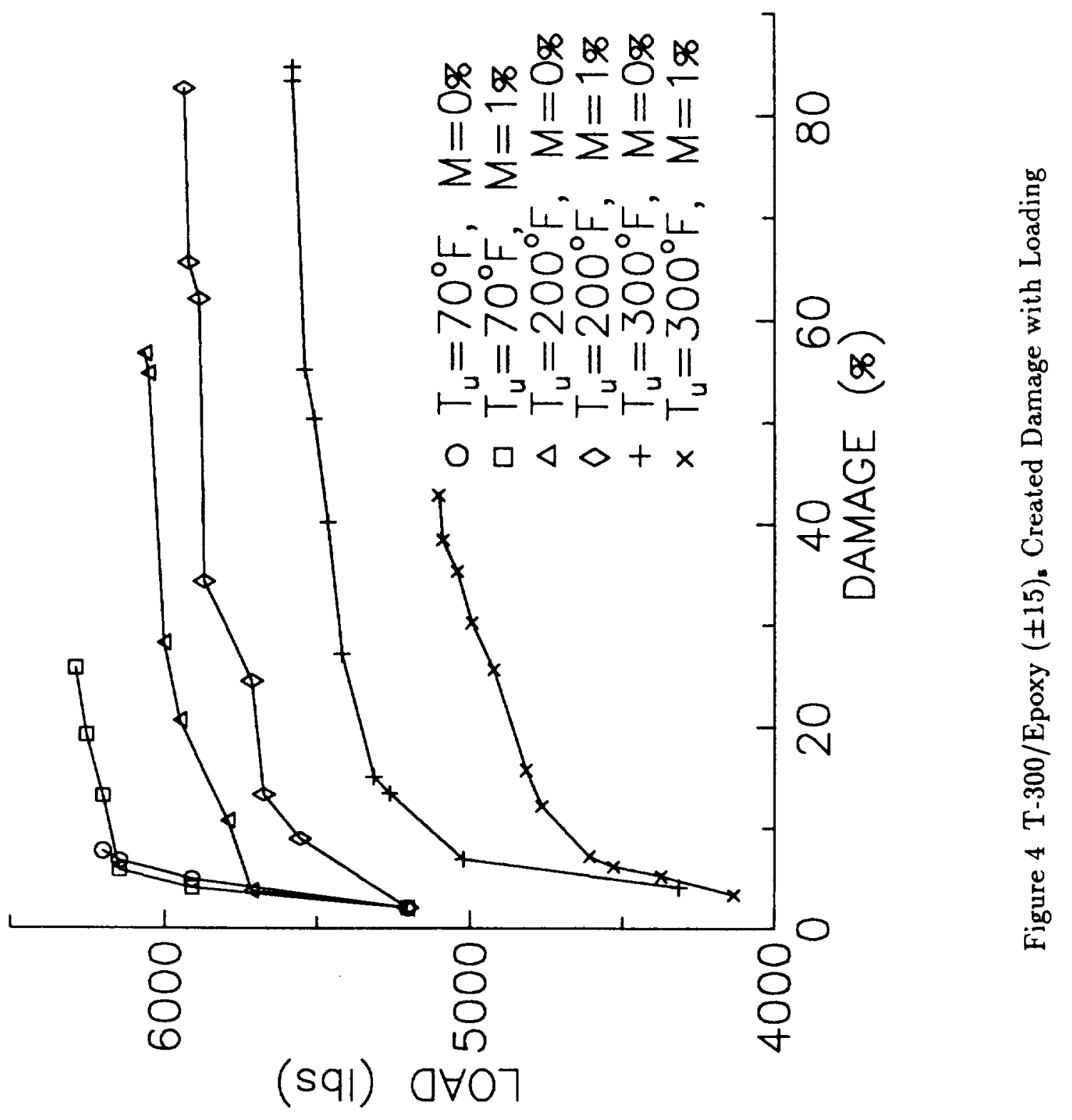




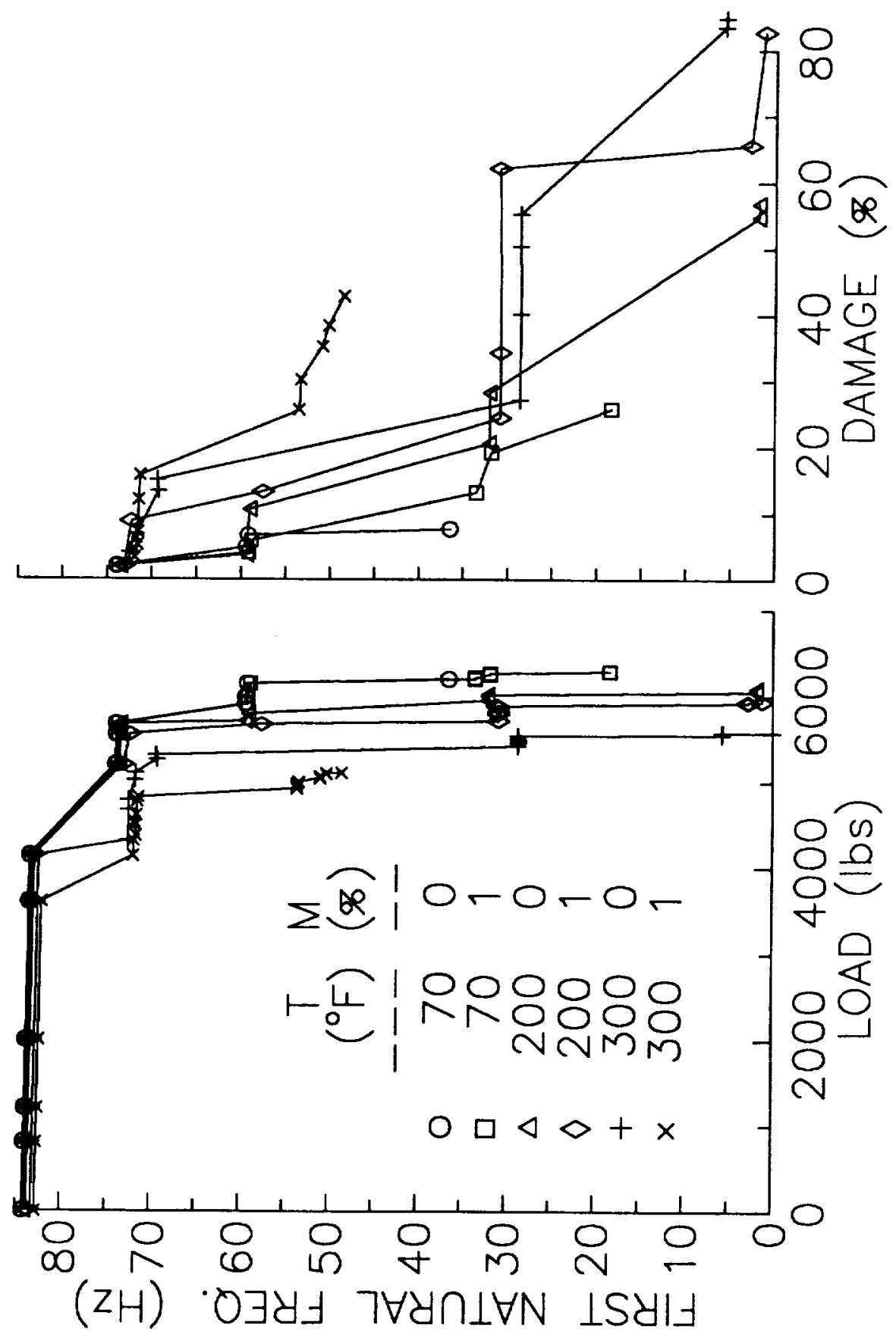

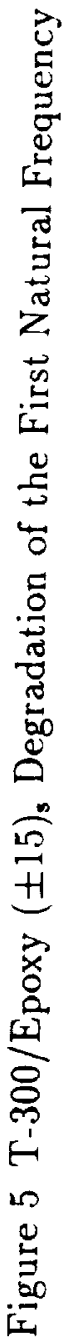




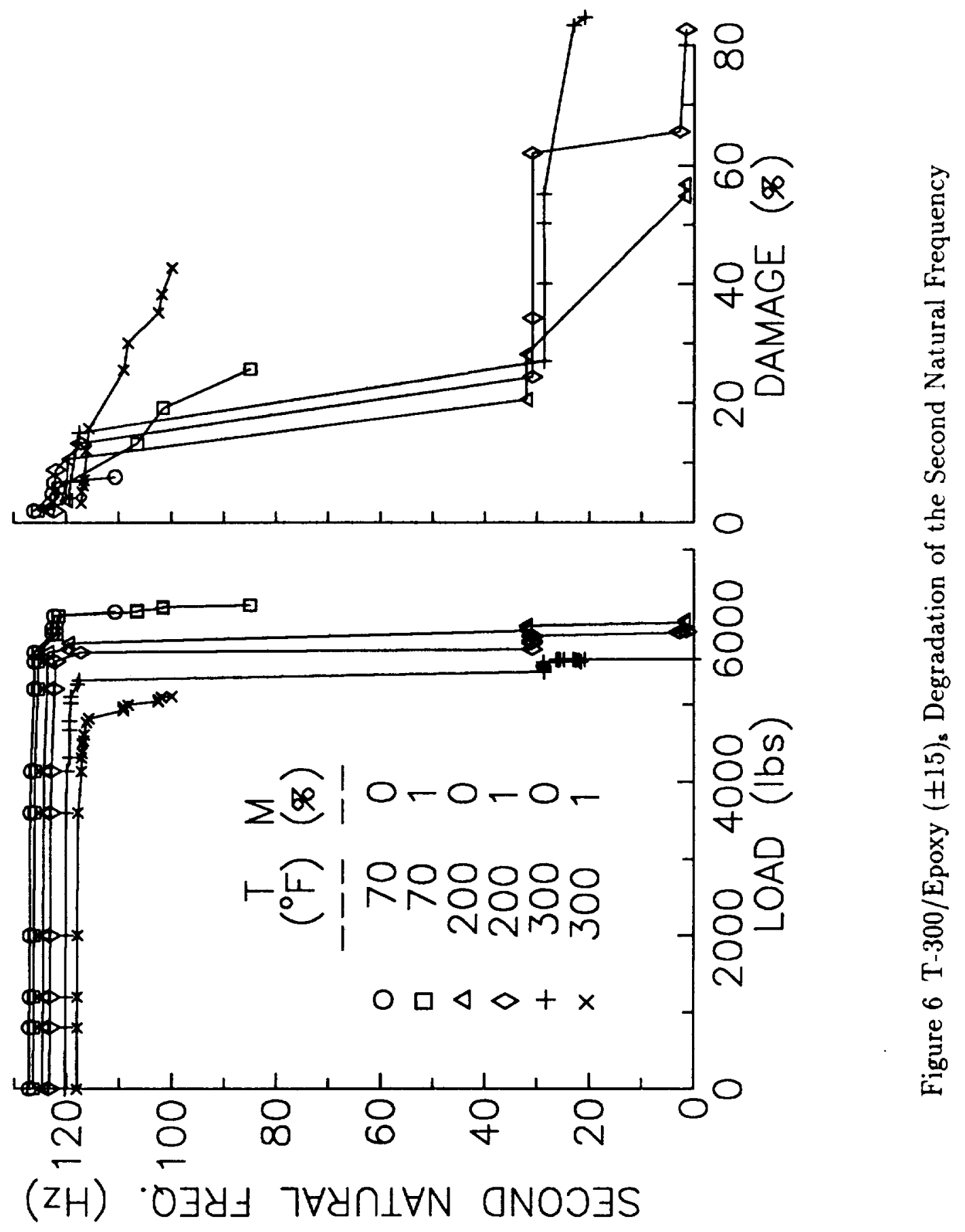




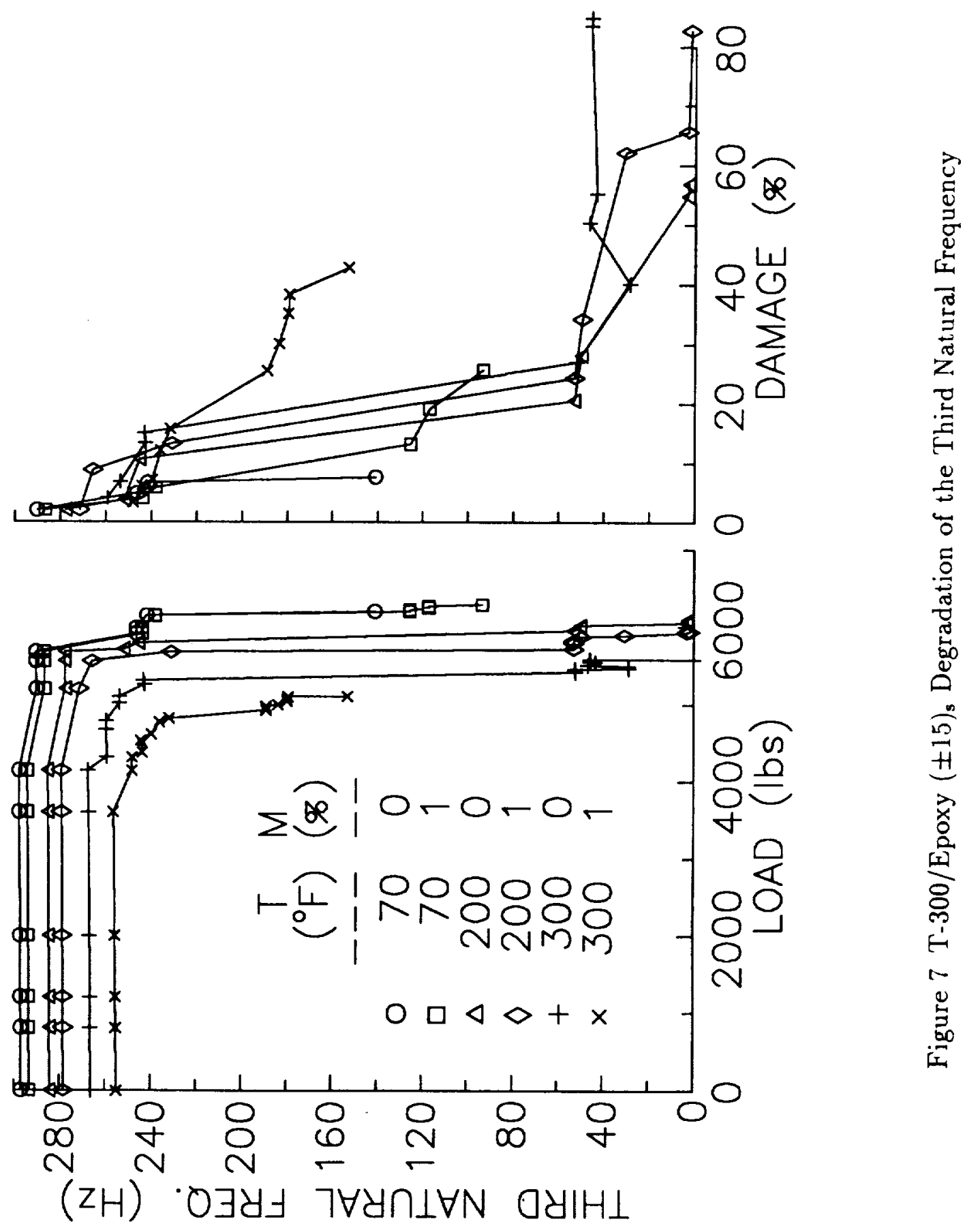




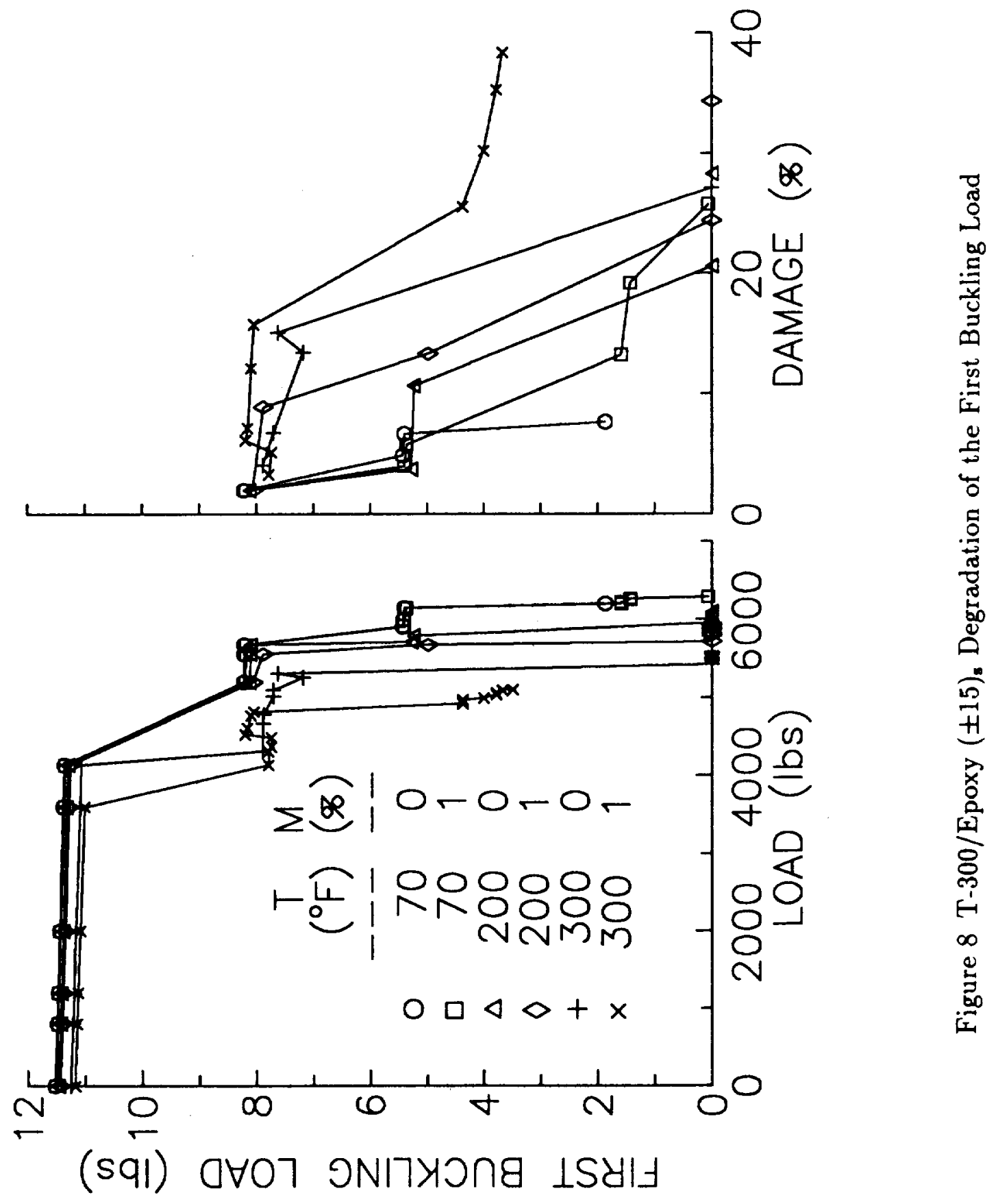




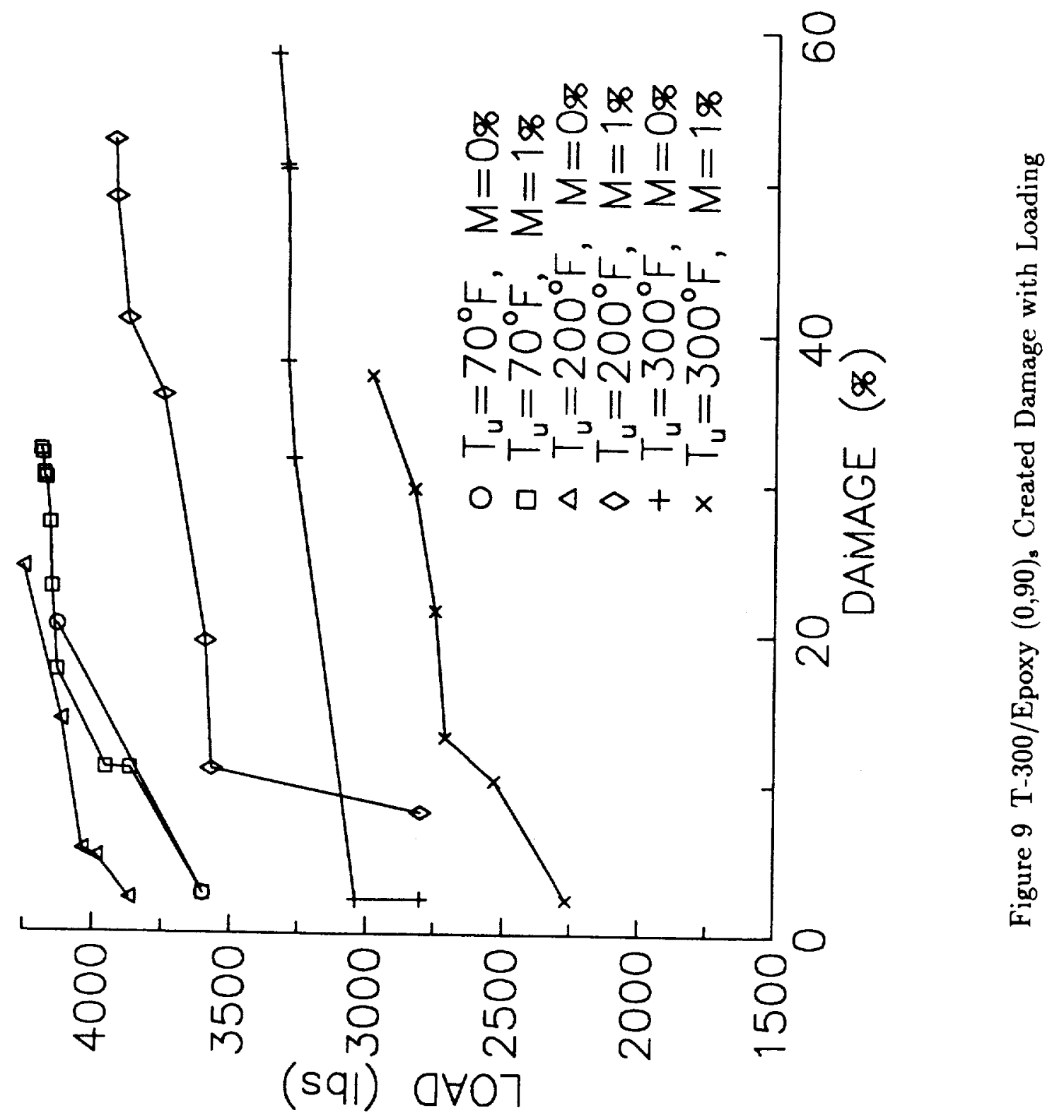




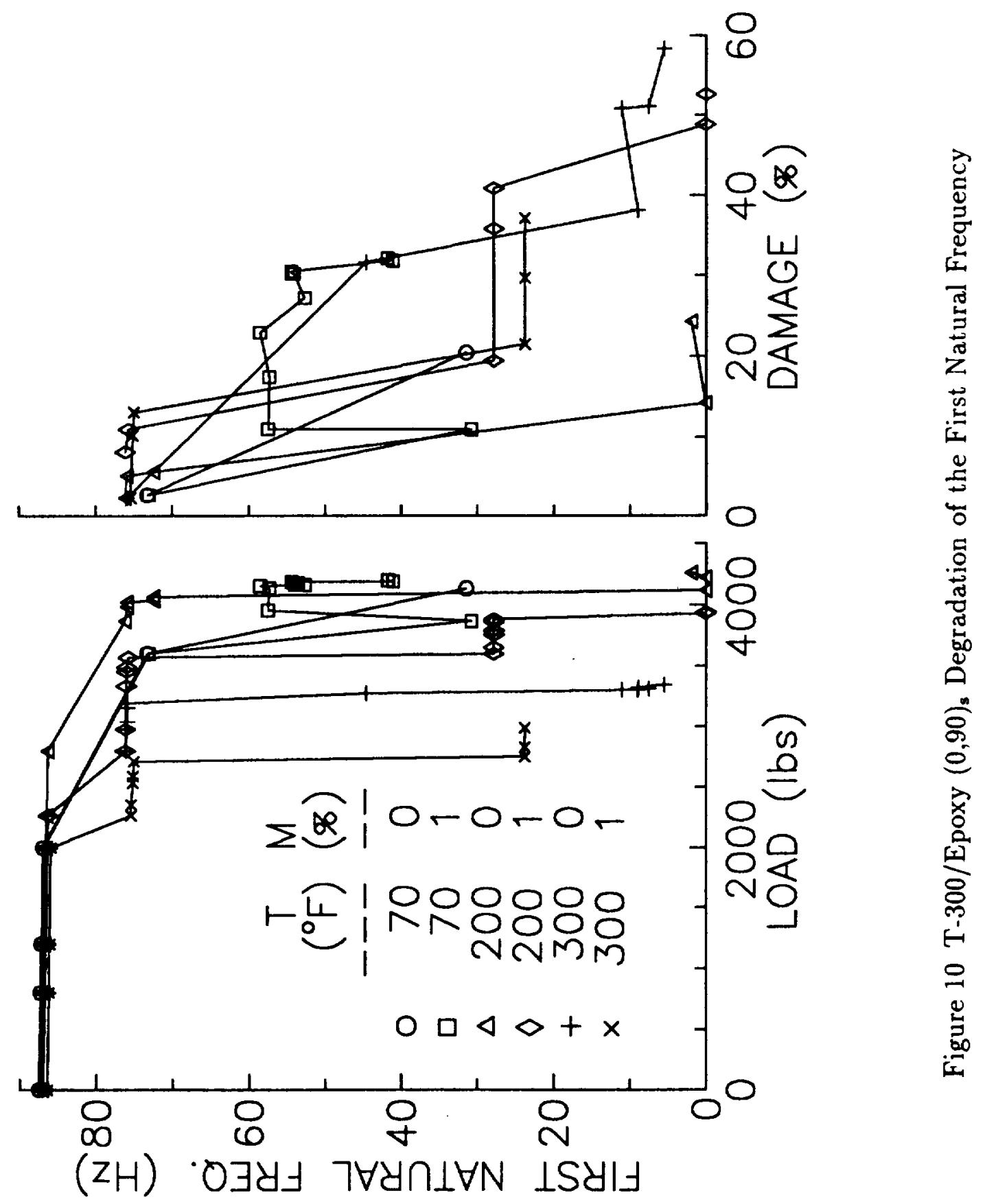




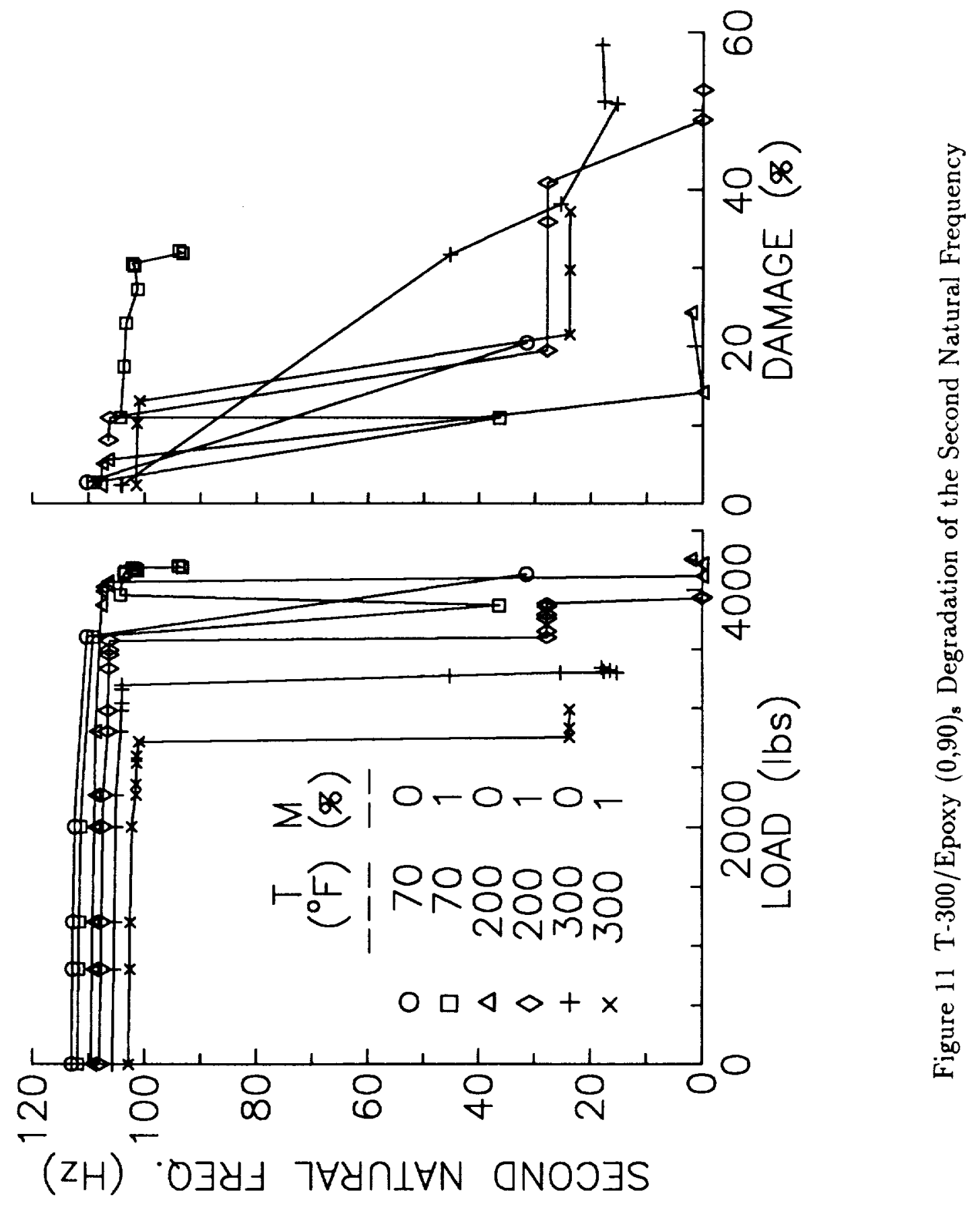




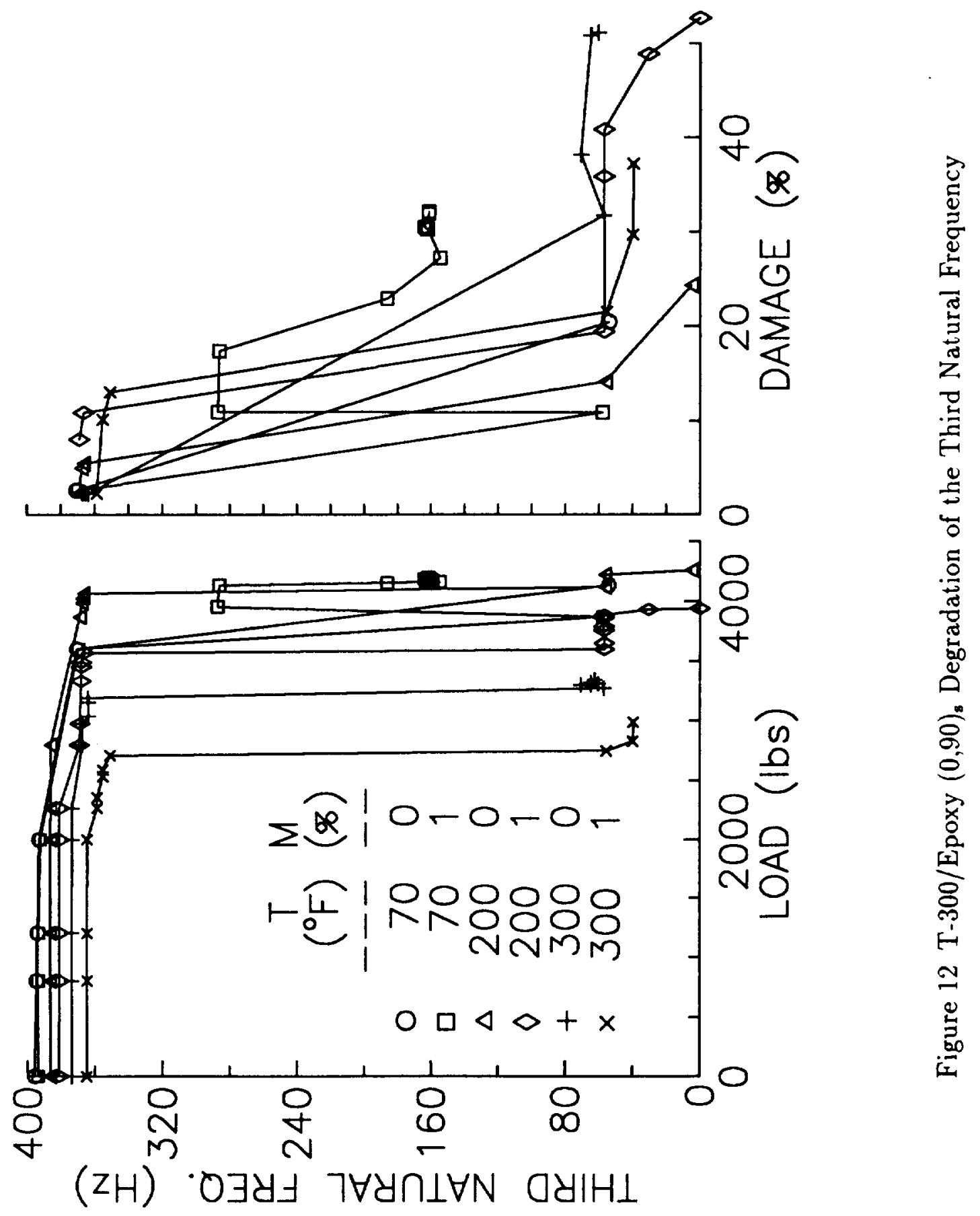




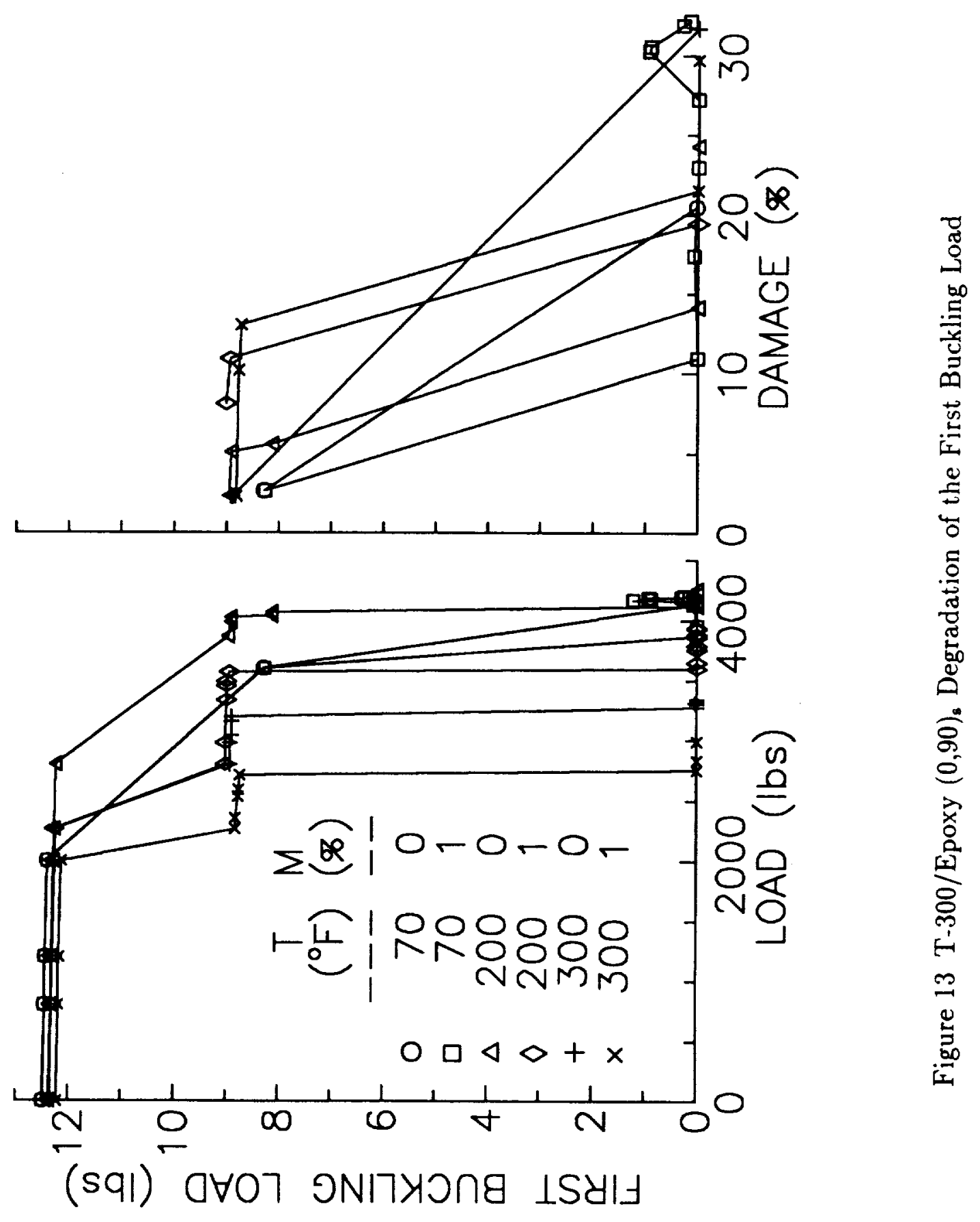




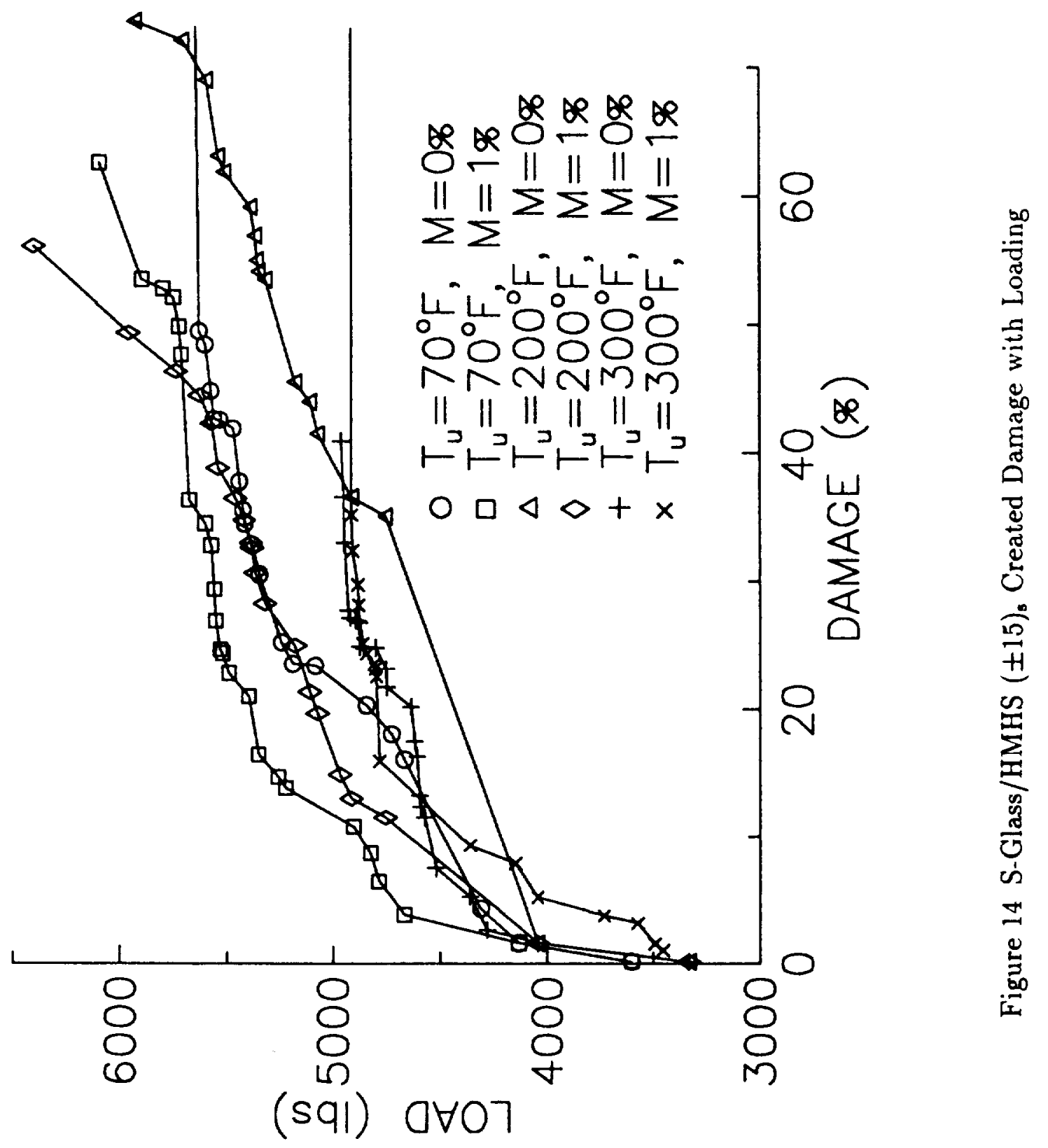




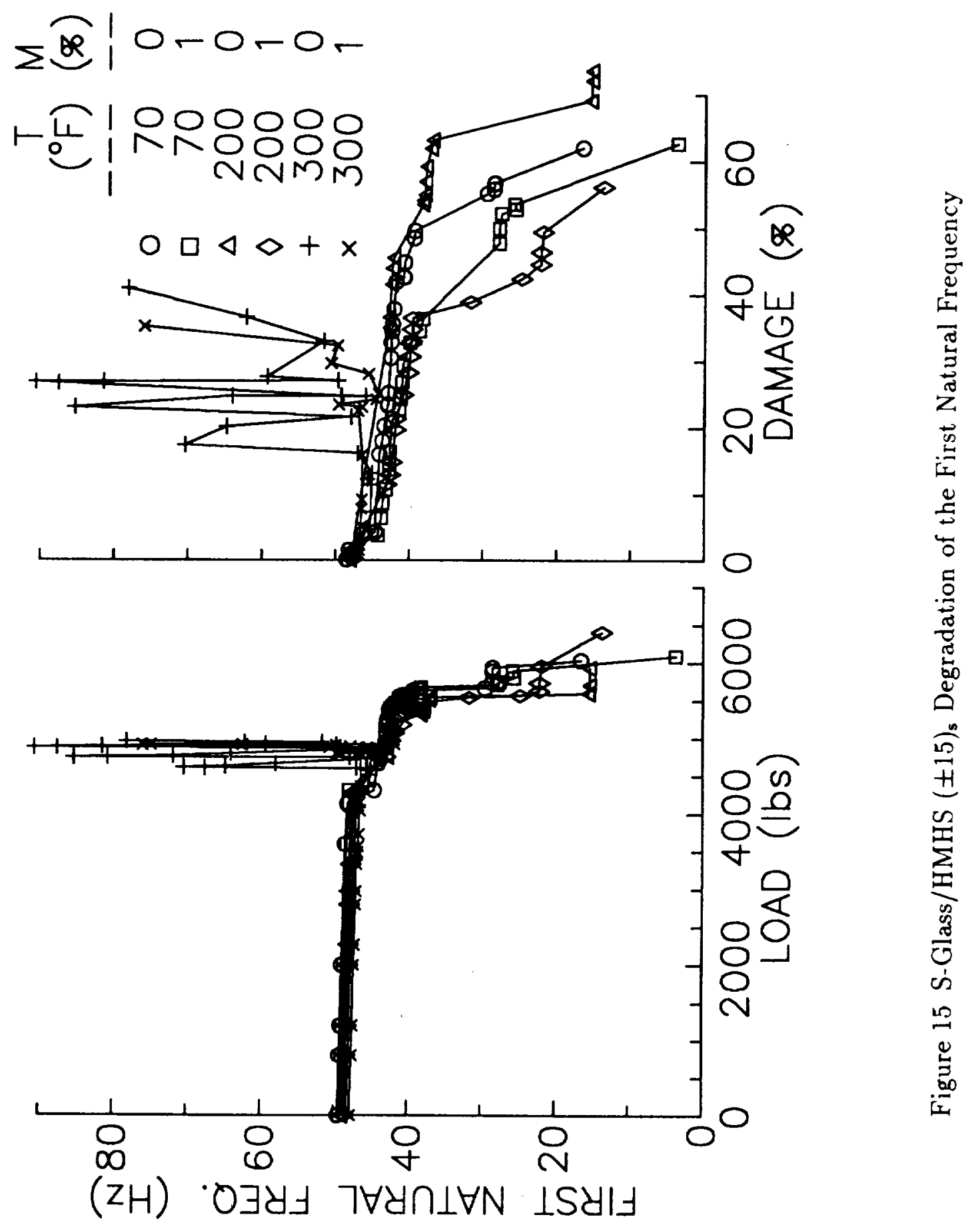




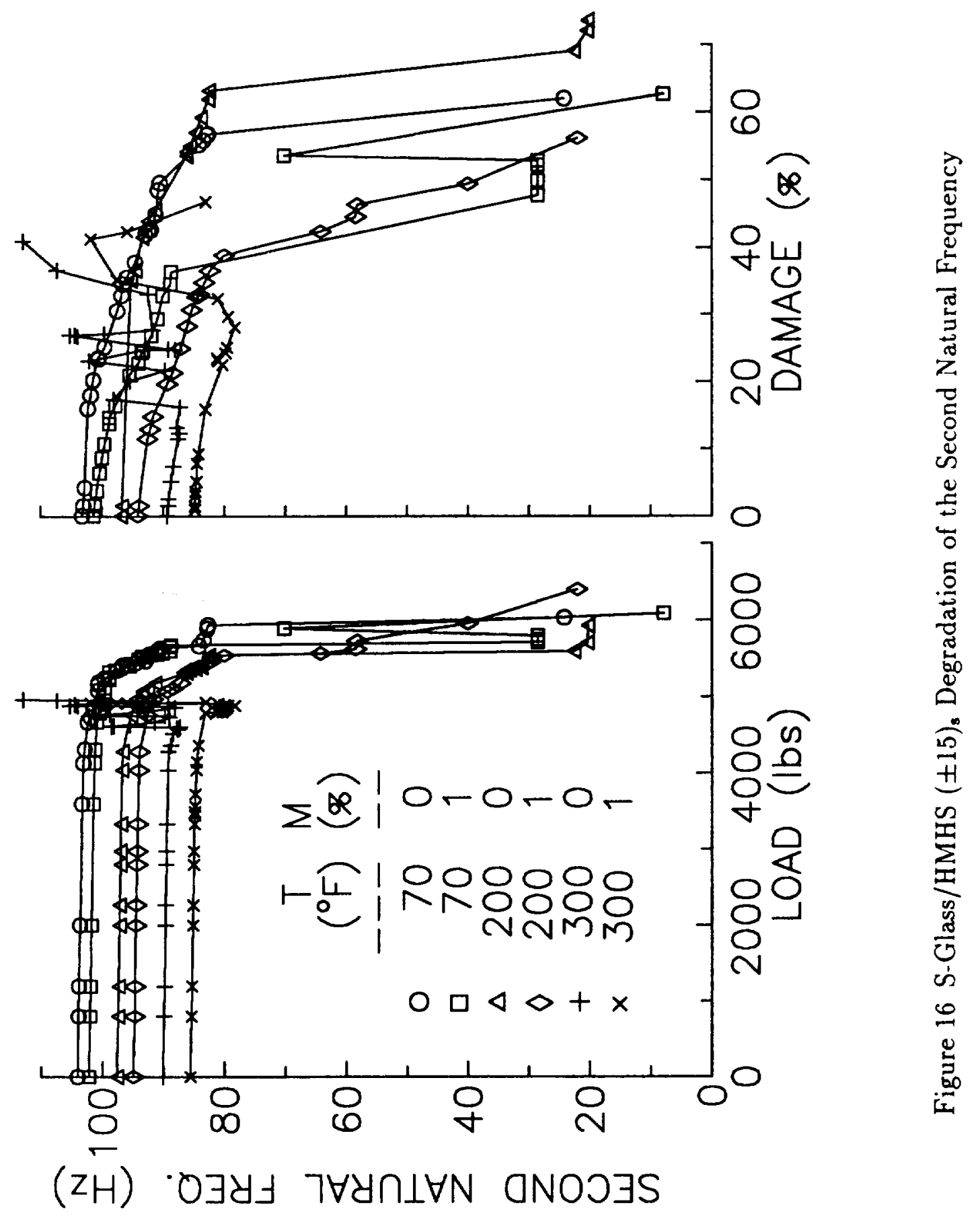




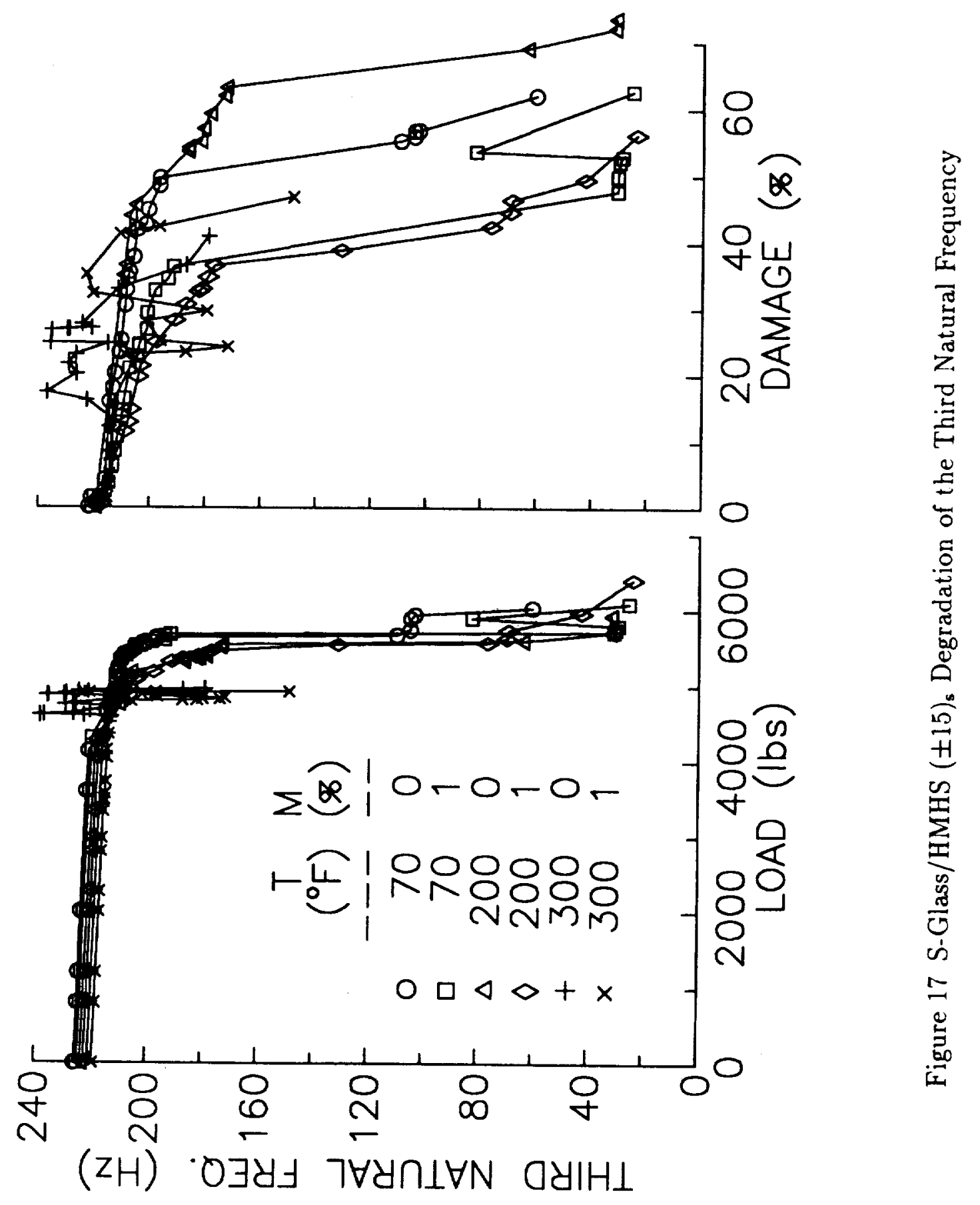




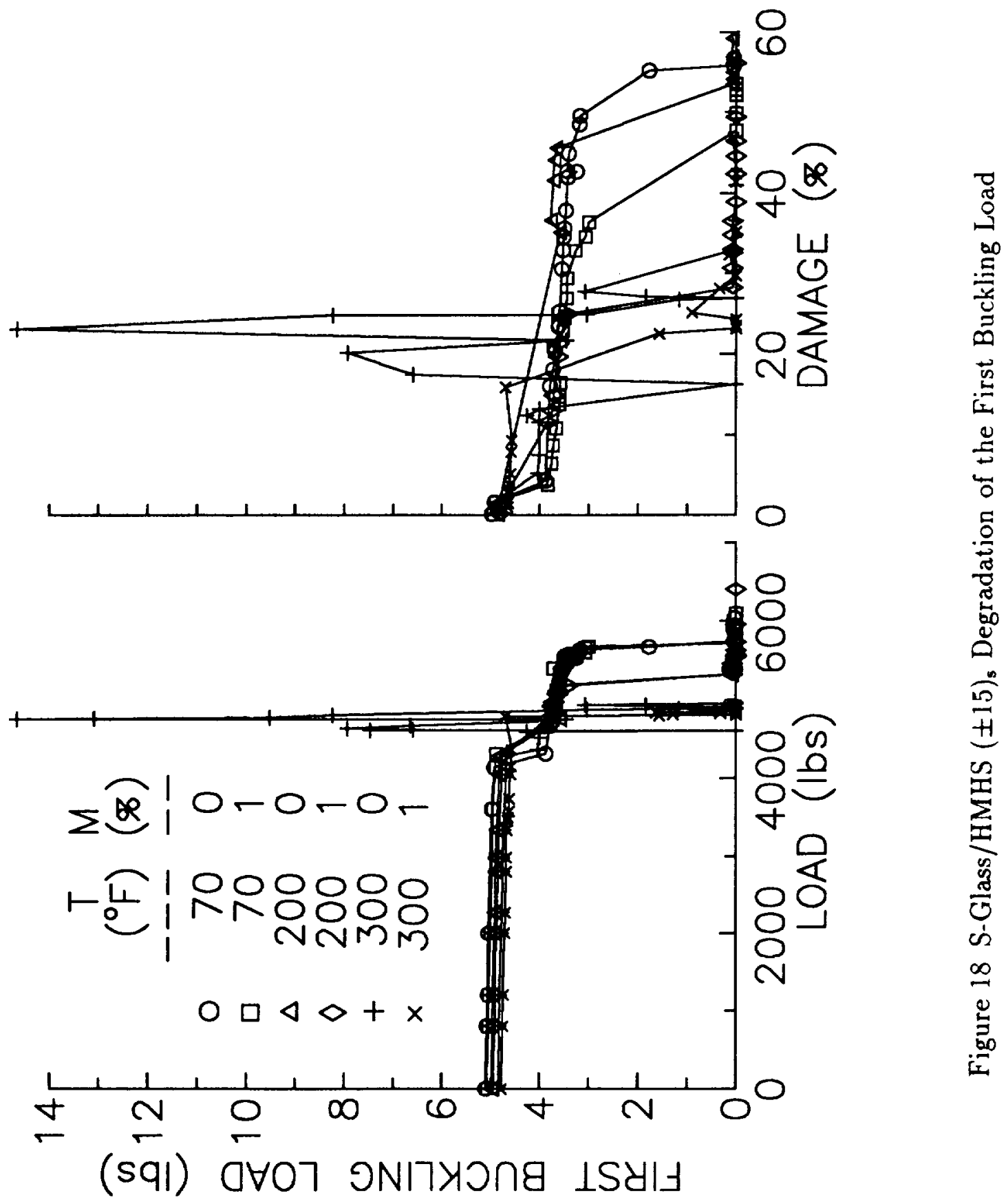


Public reporting burden for this collection of information is estimated to average 1 hour per response, including the time for reviewing instructions, searching existing data sources, gathering and maintaining the data noeded, and completing and reviewing the colloction of intormation. Send comments regarding this burden estimate or any other aspoct of this collection of Information, inctuding suggestions for reducing this burden, to Washington Headquarters Services, Directorate for information Operations and Reports, 1215 Jefferson Davis Highway, Sulte 1204, Arlington, VA 22202-4302, and to the Otfice of Management and Budget, Paperwork Reduction Project (0704-0188), Washington, DC 20503.

\begin{tabular}{|l|l|r|}
\hline 1. AGENCY USE ONLY (Leave blank) & 2. REPORT DATE & $\begin{array}{r}\text { 3. REPORT TYPE AND DATES COVERED } \\
\text { Technical Memorandum }\end{array}$
\end{tabular}

\section{TITLE AND SUBTITLE}

Progressive Fracture in Composites Subjected to Hygrothermal Environment

6. AUTHOR(S)

Levon Minnetyan, Pappu L.N. Murthy, and Christos C. Chamis
WU-505-63-5B

8. PERFORMING ORGANIZATION REPORT NUMBER

E-6553

National Aeronautics and Space Administration

Lewis Research Center

Cleveland, Ohio $44135-3191$

5. FUNDINO NUMBERS

\section{PERFoRMING ORgANIZATION NAME(S) AND ADDRESS(ES)}$$
\text { E-6553 }
$$

9. SPONSORING/MONITORING AGENCY NAMES(S) AND ADDRESS(ES)

National Aeronautics and Space Administration

Washington, D.C. 20546-0001

10. SPONSORING/MONITORING AGENCY REPOAT NUMBER

NASA TM- 105230

\section{SUPPLEMENTARY NOTES}

Prepared for the 32nd Structures, Structural Dynamics, and Materials Conference cosponsored by AIAA, ASME, ASCE, AHS, and ASC, Baltimore, Maryland, April 8-10, 1991. Levon Minnetyan, Clarkson University, Potsdam, New York 13676; Pappu L.N. Murthy and Christos C. Chamis, NASA Lewis Research Center. Responsible person, Pappu L.N. Murthy, (216) 433-3332.

12a. DISTRIBUTION/AVAILABILITY STATEMENT

12b. DISTRIBUTION CODE

Unclassified - Unlimited

Subject Category 24

\section{ABSTRACT (Maximum 200 words)}

The influence of hygrothermal environmental conditions on the load carrying ability and response of composite structures are investigated via computational simulation. An integrated computer code is utilized for the simulation of composite structural degradation under loading. Damage initiation, damage growth, fracture progression, and global structural fracture are included in the simulation. Results demonstrate the significance of hygro-thermal effects on composite structural response, toughness, and durability.

\section{SUBJECT TERMS}

Composite materials; Computational simulation; Damage; Degradation; Durability; Fracture; Laminates; Hygrothermal environment; Structural response

\begin{tabular}{|c|c|}
\hline 17. SECURITY CLASSIFICATION & 18. SECURITY CLASSIFICATION \\
OF REPORT & OF THIS PAGE \\
Unclassified & Unclassified
\end{tabular}

NSN 7540-01-280-5500
19. SECURITY CLASSIFICATION OF ABSTRACT Unclassified
15. NUMBER OF PAGES

34

16. PRICE CODE

$\mathrm{A} 03$

20. LIMITATION OF ABSTRACT 

National Aeronautics and

Space Administration

Lewls Research Center

Cleveland, Ohio 44135

Omiolel Cuebrow

Penethy for Privete bee sece

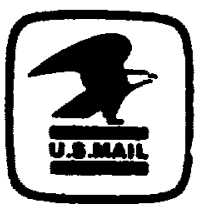

Postage and Fees Pard National Aeronaulics ano Space Admunisiration

NASA 451 